\title{
The influence of cultural conditions on the expression in Salmonella typhimurium of an antigen related to cholera toxin
}

\author{
G.-M. QI*, G. J. CLARKE, T. S. WALLIS and J. STEPHEN†
}

\section{Department of Microbiology, University of Birmingham, PO Box 363, Birmingham B15 2TT}

\begin{abstract}
Summary. The choice of strain, culture conditions, composition of medium and size of inoculum all affected the expression of a cholera-toxin-related antigen (CTRA) in Salmonella typhimurium. A previous study had shown that the number of organisms expressing CTRA in Casamino acid Yeast Extract (CYE) medium decreased between $4 \mathrm{~h}$ and $6 \mathrm{~h}$ in uninterrupted culture. In the present experiments, organisms harvested at 4-5 h were subcultured into fresh CYE medium and incubated for a further $2 \mathrm{~h}$; the total number of organisms increased, and the decrease in the proportion of organisms expressing CTRA was reduced. Use of Hartley Digest Broth in place of CYE medium increased the proportion of organisms expressing CTRA in all strains tested, in both the uninterrupted and the subculture procedures. The higher the initial inoculum, the lower was the proportion of organisms expressing CTRA. The presence of the antigen in cells remained constant for about $18 \mathrm{~h}$ after transfer from $37^{\circ} \mathrm{C}$ to $4^{\circ} \mathrm{C}$. These data have important implications for the production and purification of CTRA : they show that it was expressed during log-phase of growth, and they suggest that expression was regulated by a non-growth-limiting factor. Moreover, some avirulent strains were better producers of the antigen than virulent ones. The significance of the data is discussed in relation to the in-vivo situation.
\end{abstract}

\section{Introduction}

Full expression of the virulence of Salmonella typhimurium, as judged by accumulation of fluid in rabbit ileal loops, did not correlate with the mere ability of bacteria to associate with ileal mucosa (Worton et al., 1989); but it did correlate with the ability to induce a potent leucocyte influx (Wallis et $a l ., 1989)$ which probably reflects the ability of organisms to invade. However, it was also a function of the phenotype of the virulent strains. Previous work (Clarke et al., 1988; Wallis et al., 1989) suggested that a cholera-toxin-related antigen (CTRA) might be a factor involved in fluid secretion; also other workers have presented evidence for the production of a cholera toxin (CT)like toxin by $S$. typhimurium (Sandefur and Peterson, 1976; Finkelstein et al., 1983; Chopra et al., 1987). Since the CT-like toxin (Chopra et al., 1987) and CTRA (Clarke et al., 1988) are not identical to $\mathrm{CT}$, further biochemical and biological character-

Received 7 Oct. 1988; accepted 11 May 1989

* Present address: Institute of Epidemiology and Microbiology, PO Box 5, Changping, Beijing, China.

$\dagger$ Correspondence should be sent to Dr J. Stephen. isation of CTRA is necessary, and such work would benefit from a clearer understanding of the expression of CTRA. This would allow maximal production in normal laboratory situations, without access to facilities for handling pathogens in large batch or continuous culture.

Nutritional factors play an important role in the expression of many bacterial toxins. For expression of CT in vitro by Vibrio cholerae, media have been defined (Callahan and Richardson, 1973; Iwanaga and Yamamoto, 1985; Iwanaga et al., 1986) and optimal cultural conditions have been developed (Callahan and Richardson, 1973; Fernandes and Smith, 1977; Shimamura et al., 1985); some factors, e.g., thiols, are deleterious to CT production (Shimamura et al., 1986). Enhancement of the expression of the heat-labile toxin (LT) produced by Escherichia coli has also been studied (Gilligan and Robertson, 1979).

Similarly, the influence of varied cultural conditions on the expression of CT-like toxin by Salmonella spp. has been investigated (Molina and Peterson, 1980; Koo and Peterson, 1981), and also the influence of various antibiotics (Molina and Peterson, 1980; Houston et al., 1981; Peterson et 
al., 1981; Sobeh and Vadehra, 1984). We report here an investigation into the influence of cultural conditions on the expression of CTRA in $S$. typhimurium.

\section{Materials and methods}

\section{Bacteria}

Six strains of $S$. typhimurium, described by Clarke et al. (1988), were used. Briefly, on the basis of the rabbit ileal loop test, strains W118 and TML which were invasive and induced fluid secretion $(++$ biotype) were considered virulent; strains SL1027, LT7 and M206 which were invasive but induced negligible fluid secretion (+ - biotype) were considered avirulent; and strain Thax-1 which was non-invasive and did not induce fluid secretion ( - - biotype) was also considered avirulent.

\section{Bacterial culture}

Strains of S. typhimurium, stored at $-20^{\circ} \mathrm{C}$ or $-70^{\circ} \mathrm{C}$ (Wallis et al., 1986), were thawed at room temperature and inoculated into $80 \mathrm{ml}$ of medium: Casamino acids (Oxoid) $10 \mathrm{~g} / \mathrm{L}$, yeast extract (Lab M, Bury) $1.5 \mathrm{~g} / \mathrm{L}$, $\mathrm{MgSO}_{4} 0.08 \mathrm{~g} / \mathrm{L}, \mathrm{pH} 8.0$ (CYE); or Hartley Digest Broth (HDB; Oxoid). Organisms were cultured overnight at $37^{\circ} \mathrm{C}$, with shaking $(120 \mathrm{rpm})$, and the stated number of organisms was transferred to $200 \mathrm{ml}$ of CYE or HDB medium and incubated at $37^{\circ} \mathrm{C}$, with shaking.

Subculture. After incubation for $4-5 \mathrm{~h}$, cells were harvested by centrifugation $\left(10000 \mathrm{~g}, 10 \mathrm{~min}, 4^{\circ} \mathrm{C}\right)$, resuspended in fresh medium at $37^{\circ} \mathrm{C}$, and incubated for a further 2 or $3 \mathrm{~h}$ at $37^{\circ} \mathrm{C}$, with shaking. This resuspension and re-incubation was sometimes repeated once or twice (see Results).

\section{Antiserum to cholera toxin (CT)}

This was prepared by immunisation of New Zealand White rabbits $(2 \cdot 0-2 \cdot 5 \mathrm{~kg})$ with immunopurified cholera toxoid, as described by Clarke et al. (1988).

\section{Bacterial counts}

Quantitative assessment of organisms expressing CTRA. Cultures were assessed for CTRA by the fluorescentlylabelled-antibody technique of Clarke et al. (1988). Briefly, cells fixed to glass slides with dry acetone were washed in fluorescent-antibody phosphate-buffered saline (FAPBS: $\mathrm{NaCl} 8.5 \mathrm{~g} / \mathrm{L}, \quad \mathrm{Na}_{2} \mathrm{HPO}_{4} \quad 1.07 \mathrm{~g} / \mathrm{L}$, $\mathrm{NaH}_{2} \mathrm{PO}_{4} \cdot 2 \mathrm{H}_{2} \mathrm{O} 0.39 \mathrm{~g} / \mathrm{L} ; \mathrm{pH} 7 \cdot 1$ ), placed in blocking solution of BSA $3 \% \mathrm{w} / \mathrm{v}$, washed in FAPBS, incubated with anti-CT, washed in FAPBS and probed with FITClabelled goat-anti-rabbit serum (Wellcome). After mounting, counts of fluorescently labelled bacteria and total bacteria were obtained from photographs of the same fields taken under UV and phase-contrast illumination respectively. From the mean counts for three fields, the ratio of fluorescent to non-fluorescent organisms was calculated, thus giving the proportion of antigen-bearing organisms.

Total counts were made in a Thoma chamber.

\section{Storage of bacterial suspensions at $4^{\circ} \mathrm{C}$}

After growth in CYE medium, bacteria were centrifuged $\left(10000 \mathrm{~g}, 10 \mathrm{~min}, 4^{\circ} \mathrm{C}\right)$, washed in FAPBS $\left(4^{\circ} \mathrm{C}\right.$, $2 \mathrm{~min}$ ), resuspended in FAPBS and stored at $4^{\circ} \mathrm{C}$. At various intervals up to $18 \mathrm{~h}$, samples were examined for CTRA by fluorescent-antibody labelling (Clarke et al., 1988).

\section{Comparison of inocula of different sizes}

Except where indicated, experiments were performed on strain SL1027 because it had been shown previously to be a good producer of CTRA (Clarke et al., 1988). Within each experiment, comparisons of inocula were made on the same day from one stock culture, with the same preparation of medium.

\section{Results}

\section{Influence of inoculum size and subculture}

Different numbers of organisms of strain SL1027 were inoculated into CYE medium, and incubated for $4 \mathrm{~h}$; the organisms were harvested, resuspended in fresh medium, and incubated for a further $2-3 \mathrm{~h}$. This subculture procedure was repeated, once or twice in different experiments (table I).

The effect of subculture was to increase the total numbers of organisms, and in most experiments to lessen the drop in the proportion of organisms expressing CTRA as compared with that observed between $4 \mathrm{~h}$ and $6 \mathrm{~h}$ in uninterrupted culture $(72 \%$ to $29 \%$; Clarke et al., 1988). Increase in size of inoculum, over the range $10^{6}-10^{8}$ organisms $/ \mathrm{ml}$, tended to reduce the proportion of organisms expressing CTRA.

\section{Influence of alternative media}

Strain SL1027. With an inoculum of $10^{6}$ bacteria/ $\mathrm{ml}$, growth in CYE and HDB media was compared after initial incubation for $4 \mathrm{~h}$ and after further incubation of subcultures for $2 \mathrm{~h}$ (table II). The total counts were similar in the two media; but the proportion of organisms expressing CTRA was greater in HDB than in CYE after $4 \mathrm{~h}$, and was reduced to a lesser extent after further subculture.

The production of CTRA in HDB medium was observed over a period of $7 \mathrm{~h}$ (figure). $\mathrm{Up}$ to $5 \mathrm{~h}$, 
Table I. Influence of inoculum-size and serial subculture on the expression of CTRA in S. typhimurium strain SL1027 grown in CYE medium

\begin{tabular}{|c|c|c|c|c|c|c|c|}
\hline \multirow{2}{*}{$\begin{array}{l}\text { Experiment } \\
\text { no.* }\end{array}$} & \multirow{2}{*}{$\begin{array}{l}\text { Incubation } \\
\text { time (h) }\end{array}$} & \multicolumn{3}{|c|}{$\begin{array}{l}\text { Final total bacterial count (organisms } / \mathrm{ml} \text { ) } \\
\text { from initial inoculum of (orgs } / \mathrm{ml} \text { ) }\end{array}$} & \multicolumn{3}{|c|}{$\begin{array}{l}\text { Percentage of total count expressing } \\
\text { CTRA } \ddagger \text { after initial inoculum of (orgs } / \mathrm{ml} \text { ) }\end{array}$} \\
\hline & & $10^{6}$ & $10^{7}$ & $10^{8}$ & $10^{6}$ & $10^{7}$ & $10^{8}$ \\
\hline \multirow[t]{3}{*}{1} & 4 & $2 \times 10^{8}$ & $2 \times 10^{9}$ & $6 \times 10^{9}$ & 67 & 63 & 32 \\
\hline & $2 \dagger$ & $4 \times 10^{9}$ & $1 \times 10^{10}$ & $2 \times 10^{10}$ & 60 & 40 & 45 \\
\hline & $2 \dagger$ & $3 \times 10^{10}$ & $3 \times 10^{10}$ & $5 \times 10^{10}$ & 48 & 64 & 53 \\
\hline \multirow[t]{3}{*}{2} & 4 & $2 \times 10^{8}$ & $3 \times 10^{9}$ & $1 \times 10^{10}$ & 75 & 62 & 33 \\
\hline & $2 \dagger$ & $4 \times 10^{9}$ & $1 \times 10^{10}$ & $3 \times 10^{10}$ & 48 & 42 & 35 \\
\hline & $2 \dagger$ & $2 \times 10^{10}$ & $3 \times 10^{10}$ & $5 \times 10^{10}$ & 41 & 26 & 35 \\
\hline \multirow[t]{3}{*}{3} & 4 & $2 \times 10^{8}$ & $2 \times 10^{9}$ & $8 \times 10^{9}$ & 73 & 69 & 45 \\
\hline & $2 \dagger$ & $5 \times 10^{9}$ & ND & $1 \times 10^{10}$ & 52 & ND & 34 \\
\hline & $2 \dagger$ & $2 \times 10^{10}$ & $3 \times 10^{10}$ & $2 \times 10^{10}$ & ND & 27 & 57 \\
\hline \multirow[t]{4}{*}{4} & 4 & $3 \times 10^{8}$ & $4 \times 10^{9}$ & $1 \times 10^{10}$ & 60 & 28 & 22 \\
\hline & $2 \dagger$ & $6 \times 10^{9}$ & $2 \times 10^{10}$ & $3 \times 10^{10}$ & 44 & 34 & 57 \\
\hline & $3 t$ & $1 \times 10^{10}$ & $3 \times 10^{10}$ & $5 \times 10^{10}$ & 16 & 19 & 12 \\
\hline & $3 \dagger$ & $3 \times 10^{10}$ & ND & $6 \times 10^{10}$ & 16 & ND & 15 \\
\hline
\end{tabular}

$\mathrm{ND}=$ Not done.

* Experiments were performed on separate days with separate preparations of media and fresh inocula.

$\dagger$ Cultures harvested after previous incubation and resuspended for stated time in fresh medium.

$\ddagger$ Expression of CTRA measured as the percentage of bacteria showing fluorescence after treatment with fluorescent antibody (see Materials and methods).

Table II. Influence of culture medium $\S$ on growth of organisms and expression of CTRA in S. typhimurium strain SL1027 from an initial inoculum of $10^{6}$ organisms $/ \mathrm{ml}$

\begin{tabular}{|c|c|c|c|c|c|}
\hline \multirow{2}{*}{$\begin{array}{l}\text { Experiment } \\
\text { no.* }\end{array}$} & \multirow{2}{*}{$\begin{array}{l}\text { Incubation } \\
\text { time }(\mathrm{h})\end{array}$} & \multicolumn{2}{|c|}{$\begin{array}{l}\text { Final total bacterial count } \\
\text { (organisms } / \mathrm{ml} \text { ) in }\end{array}$} & \multicolumn{2}{|c|}{$\begin{array}{l}\text { Percentage of total count } \\
\text { expressing CTRA } \ddagger \text { in }\end{array}$} \\
\hline & & CYE & HDB & CYE & HDB \\
\hline \multirow[t]{3}{*}{2} & 4 & $2 \times 10^{8}$ & $3 \times 10^{8}$ & 75 & 95 \\
\hline & $2 \dagger$ & $4 \times 10^{9}$ & $6 \times 10^{9}$ & 48 & 74 \\
\hline & $2 \dagger$ & $2 \times 10^{10}$ & $3 \times 10^{10}$ & 41 & 60 \\
\hline \multirow[t]{3}{*}{3} & 4 & $2 \times 10^{8}$ & $2 \times 10^{8}$ & 73 & 76 \\
\hline & $2 \dagger$ & $5 \times 10^{9}$ & $4 \times 10^{9}$ & 52 & 69 \\
\hline & $2 \dagger$ & $2 \times 10^{10}$ & $2 \times 10^{10}$ & ND & 57 \\
\hline
\end{tabular}

$\mathrm{ND}=$ Not done.

* Data for growth in CYE medium reproduced from table I, experiments 2 and 3.

$\dagger$ Cultures harvested after previous incubation and resuspended for stated time in fresh medium.

$\ddagger$ As indicated in table $\mathrm{I}$.

$\S$ Media were inoculated at the same time on the same day.

the numbers of bacteria expressing CTRA were similar to the total counts. After $5 \mathrm{~h}$, the numbers expressing CTRA remained approximately constant, whereas the total counts continued to increase, though less sharply.

Other strains of $S$. typhimurium. From the results shown in the figure, a single period of incubation $(5 \mathrm{~h})$ was chosen to compare CTRA production in other strains. A similarly increased proportion of organisms expressing CTRA was observed for each strain in HDB medium compared with CYE medium (table III). Some avirulent strains (SL1027, M206, Thax-1) were better producers of the antigen than virulent strains (TML, W118).

Because the maximum number of organisms expressing CTRA was reached at $5 \mathrm{~h}$ with strain 


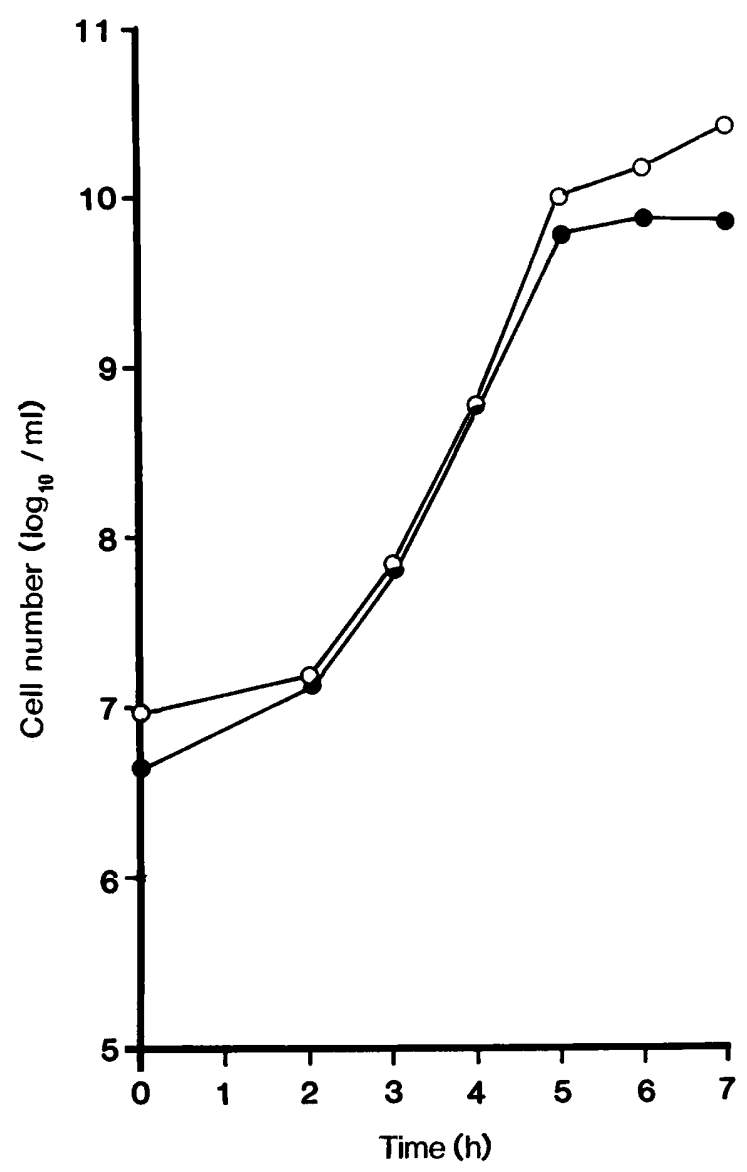

Figure. Expression of CTRA by $S$. typhimurium strain SL1027 grown in HDB medium. The numbers of organisms expressing CTRA (O) increased exponentially up to $5 \mathrm{~h}$, with little further rise; but the total count $(O)$ did show a further slight increase.

SL1027, the effect of subculture at this stage was examined (table III). The total cell count was higher in the 2-h subculture, and there was still a high proportion of organisms expressing CTRA.

\section{Stability of CTRA at $4^{\circ} \mathrm{C}$}

The stability of CTRA in cells stored at $4^{\circ} \mathrm{C}$ was observed in strain SL1027 (table IV). After growth from different inocula, the proportion of fluorescently-labelled organisms remained approximately constant over an 18-h storage period.

\section{Discussion}

The expression of CTRA in strains of $S$. typhimurium has been examined previously by a fluorescent-antibody labelling technique (Clarke $e t$ $a l .$, 1988). It was shown that a rapid increase in
Table III. Growth of bacteria and expression of CTRA in six strains of $S$. typhimurium after incubation in HDB for $5 \mathrm{~h}$ from an initial inoculum of $10^{6}$ organisms $/ \mathrm{ml}$

\begin{tabular}{|c|c|c|c|c|}
\hline \multirow[b]{2}{*}{ Strain } & \multicolumn{2}{|c|}{$\begin{array}{l}\text { Final total bacterial } \\
\text { count (organisms } / \mathrm{ml} \text { ) in }\end{array}$} & \multicolumn{2}{|c|}{$\begin{array}{l}\text { Percentage of total } \\
\text { count expressing } \\
\text { CTRA } \ddagger \text { in }\end{array}$} \\
\hline & HDB & CYE* & HDB & CYE* \\
\hline TML & $7 \times 10^{9}$ & $2 \times 10^{9}$ & 62 & 17 \\
\hline W118 & $1 \times 10^{10}$ & $1 \times 10^{9}$ & 50 & 41 \\
\hline SL1027 & $5 \times 10^{9}$ & $6 \times 10^{8}$ & 81 & 42 \\
\hline SL1027† & $2 \times 10^{10}$ & ND & 75 & ND \\
\hline M206 & $4 \times 10^{9}$ & $2 \times 10^{9}$ & 87 & 37 \\
\hline LT7 & $3 \times 10^{9}$ & $6 \times 10^{8}$ & 59 & 25 \\
\hline Thax-1 & $1 \times 10^{9}$ & $3 \times 10^{8}$ & 74 & 8 \\
\hline
\end{tabular}

$\mathrm{ND}=$ Not done

* Previous results of growth in CYE medium (Clarke et al., 1988).

$\dagger$ Subcultured at $5 \mathrm{~h}$ and incubated for a further $2 \mathrm{~h}$.

$\ddagger$ As indicated in table $\mathrm{I}$.

Table IV. The stability of expression of CTRA in $S$. typhimurium SL1027 after storage at $4^{\circ} \mathrm{C}$

\begin{tabular}{|c|c|c|c|}
\hline \multirow{2}{*}{$\begin{array}{c}\text { Duration of } \\
\text { storage* }^{*} \\
\text { (h) }\end{array}$} & \multicolumn{3}{|c|}{$\begin{array}{l}\text { Percentage of total count expressing } \\
\text { CTRAf after initial inoculum of (orgs } / \mathrm{ml} \text { ) }\end{array}$} \\
\hline & $10^{6}$ & $10^{7}$ & $10^{8}$ \\
\hline 0 & 60 & 28 & 22 \\
\hline 1 & 60 & 27 & ND \\
\hline 7 & 63 & 33 & 26 \\
\hline 18 & 67 & 34 & 21 \\
\hline
\end{tabular}

$\mathrm{ND}=$ Not done

* Organisms grown in CYE medium for $4 \mathrm{~h}$ were stored for the stated period (see Materials and methods) before examination for expression of CTRA.

$\ddagger$ As indicated in table I.

antigen production occurred, peaking in early- to mid-log phase (after about $4 \mathrm{~h}$ ); subsequently there was a decrease in the proportion of organisms expressing the antigen. In the present study, we have demonstrated conditions in which a greater proportion of organisms expressed CTRA over a longer period, the numbers of fluorescently-labelled bacteria increasing logarithmically together with total numbers, up to $c .5 \mathrm{~h}$. This substantiates the previous view that the expression of CTRA was related to growth phase.

Other parameters also influenced the expression of CTRA. In general, the greater the size of the initial inoculum, the lower was the proportion of bacteria expressing CTRA. The reason is unknown; but when examined in conjunction with the 
influence of growth phase, it is conceivable that a non-growth-limiting component of the medium regulates expression of the antigen. The more rapid exhaustion of this component with a larger inoculum may lead to expression of CTRA by a lower final proportion of bacteria.

The influence of the composition of the medium was demonstrated by a higher proportion of bacteria expressing CTRA in HDB medium than in CYE medium. Maybe a higher concentration of a non-growth-limiting factor that regulates antigen expression is present in HDB medium than in CYE medium.

These results could be important biologically. Wallis et al. (1989) showed that the number and nature of the challenge organisms is important in rabbit ileal loop tests; rapid induction of salmonellainduced fluid secretion occurred only when $\geqslant 10^{7}$ organisms of the right phenotype were injected. Thus, in a natural infection by the oral route, rapid onset of disease may occur only if sufficient organisms bearing preformed toxin are present in contaminated food; we await the development of a suitable model to study this. Alternatively, the correct phenotype of organisms for disease causa-

\section{REFERENCES}

Callahan L T, Richardson S H 1973 Biochemistry of Vibrio cholerae virulence. III. Nutritional requirements for toxin production and the effects of $\mathrm{pH}$ on toxin elaboration in chemically defined media. Infection and Immunity 7: 567572 .

Chopra A K, Houston C W, Peterson J W, Prasad R, Mekalanos J J 1987 Cloning and expression of the Salmonella enterotoxin gene. Journal of Bacteriology 169: 5095-5100.

Clarke $\mathbf{G} \mathbf{J}$ et al. 1988 Expression of an antigen in strains of Salmonella typhimurium which reacts with antibodies to cholera toxin. Journal of Medical Microbiology 25: 139-146.

Fernandes P B, Smith H L 1977 The effect of anaerobiosis and bile salts on the growth and toxin production of Vibrio cholera. Journal of General Microbiology 98: 77-86.

Finkelstein R A, Marchlewicz B A, McDonald R J, BoesmanFinkelstein M 1983 Isolation and characterization of a cholera-related enterotoxin from Salmonella typhimurium. FEMS Microbiology Letters 17: 239-241.

Gilligan P H, Robertson D C 1979 Nutritional requirements for synthesis of heat-labile enterotoxin by enterotoxigenic strains of Escherichi coli. Infection and Immunity 23: 99-107.

Houston C W, Koo F C W, Peterson J W 1981 Characterization of Salmonella toxin released by mitomycin C-treated cells. Infection and Immunity 32: 916-926.

Iwanaga M, Yamamoto K 1985 New medium for the production of cholera toxin by Vibrio cholerae $\mathrm{O} 1$ biotype El Tor. Journal of Clinical Microbiology 22: 405-408.

Iwanaga $\mathrm{M}$, Yamamoto $\mathrm{K}$, Higa $\mathrm{N}$, Ichinose $\mathrm{Y}$, Nakasone $\mathbf{N}$, Tanabe M 1986 Culture conditions for stimulating cholera toxin production by Vibrio cholerae $\mathrm{O} 1 \mathrm{El}$ Tor. Microbiology and Immunology 30: 1075-1083.

Koo F C W, Peterson J W 1981 The influence of nutritional tion may occur after ingestion of a strain of the correct genotype but initially of incorrect phenotype; retention and subsequent growth of organisms within the lumen or the mucosa of the intestine, or in both, under appropriate growth conditions in vivo, would need to occur for expression of CTRA. This could explain a more lengthy incubation period before the onset of disease, if the antigen is a virulence factor; we are attempting to study the timing and relevance of antigen-expression in vivo. Furthermore if, as suggested by Wallis et al. (1989), CTRA should prove to be an important virulence factor in the causation of fluid secretion, then the finding that some avirulent strains seem to be better producers than virulent ones (table III), again emphasises that other factors also must play a part in full expression of virulence.

Finally, our present study of the optimal cultural conditions for the expression of CTRA, in vitro, will facilitate fractionation and purification; our demonstration of the stability of the antigen at $4^{\circ} \mathrm{C}$ is encouraging.

JS gratefully acknowledges the generous financial support of the Wellcome Trust and of the MRC for a postdoctoral fellowship to GJC.

factors on synthesis of Salmonella toxin. Journal of Food Safety 3 : 215-232.

Molina N C, Peterson J W 1980 Cholera toxin-like toxin released by Salmonella species in the presence of mitomycin $\mathrm{C}$. Infection and Immunity 30: 224-230.

Peterson J W, Houston C W, Koo F C W 1981 Influence of cultural conditions on mitomycin $\mathrm{C}$-mediated bacteriophage induction and release of Salmonella toxin. Infection and Immunity 32 : 232-242.

Sandefur P D, Peterson J W 1976 Isolation of skin permeability factors from culture filtrates of Salmonella typhimurium. Infection and Immunity 14: 671-679.

Shimamura T, Watanabe S, Sasaki S 1985 Enhancement of enterotoxin production by carbon dioxide in Vibrio cholerae. Infection and Immunity 49:455-456.

Shimamura T, Watanabe S, Sasaki S 1986 Inhibition of cholera toxin production by thiols in Vibrio cholerae. Infection and Immunity 53: 700-701.

Sobeh F Y, Vadehra D V 1984 Influence of antibiotics on growth, synthesis and release of enterotoxin by Salmonella enteritidis. Indian Journal of Medical Research 80: 279-283.

Wallis T S et al. 1989 Quantification of the leucocyte influx into rabbit ileal loops induced by strains of Salmonella typhimurium of different virulence. Journal of Medical Microbiology 30: $149-156$.

Wallis T S, Starkey W G, Stephen J, Haddon S J, Osborne M P, Candy D C A 1986 Enterotoxin production by Salmonella typhimurium strains of different virulence. Journal of Medical Microbiology 21 : 19-23.

Worton K J et al. 1989 Studies on early association of Salmonella typhimurium with intestinal mucosa in vivo and in vitro: relationship to virulence. Journal of Medical Microbiology 29: $283-294$. 